\title{
Promotion of a waste recycling bank in schools: A case study in a municipality school in Thailand
}

Adisak Singseewo ${ }^{a^{*}}$

Kamolwan Klaoklang ${ }^{b}$

Suggested Citation:

New Trends and Issues Proceedings on Humanities and Social Sciences.

Abstract 
New Trends and Issues Proceedings on Humanities and Social Sciences.

1. Introduction

(

1

( 
2. Objective of the Research

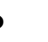

3. Research Methodology

3.1. Population and sample group

3.2. Research variables

4. Data collection

Phase 1

Phase 2

Phase 3 
New Trends and Issues Proceedings on Humanities and Social Sciences.

\section{Research Results}

5.1. Results involving the students' knowledge and attitude

\subsection{Results regarding student participation with the program}

\section{Discussion}

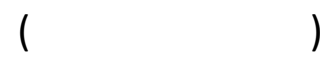


New Trends and Issues Proceedings on Humanities and Social Sciences. 


\section{Acknowledgements}

\section{References}

Factors of success of the waste recycling bank

Public participation in waste management in Nongo Sub-district, Mahasarakham.

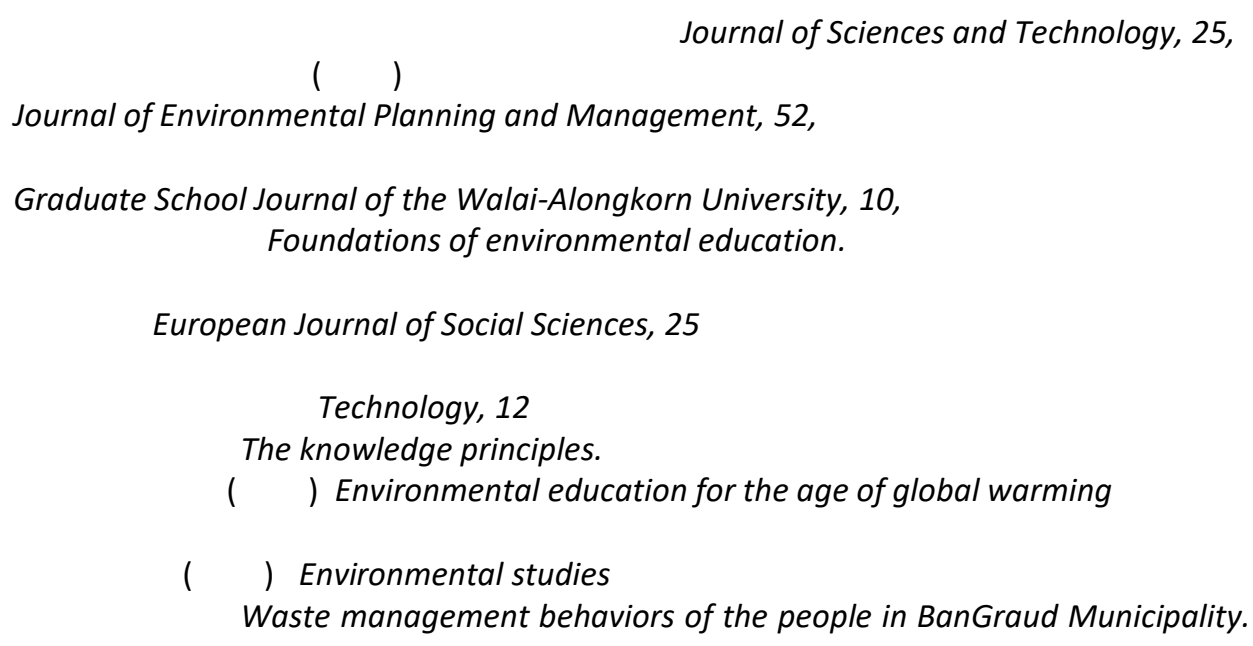

Health Sciences, 6 